\title{
Fertility Response to Economic Recessions in Finland 1991-2015
}

\author{
HEIKKI HIILAMO, VID Specialized University Oslo
}

\begin{abstract}
Previous studies have established a robust negative association between unemployment and fertility. Finland has experienced two periods of deep economic recessions within last 25 years, one in the early 1990s and the other during the Great Recession in the 2000s. This study analyzes fertility response to economic recession in Finland through total and gender specific unemployment between 1991 and 2015 with sub-regional data. The method of analysis is sub-region fixed effect regression. The changes in unemployment were associated with changes in fertility in Finland from 1991 to 2015. One percentage increase in unemployment reduced delivery rate by 0.13 percentages. The effect of unemployment on fertility was stronger during the Great recession than during the recession in the 1990s.
\end{abstract}

Keywords: economic recessions, fertility, unemployment.

\section{Introduction}

The decline of fertility as a consequence of unemployment is one of the long-term effects of economic recessions. With easy access to contraceptives, individuals in the modern Western societies pay attention to income security and stable economic conditions in establishing a family and planning to have a child. High unemployment is strongly associated with low fertility (Sobotka et al. 2011). This does not only mean that individuals cannot fulfil their aspirations to have the number of children they hope for, but comes also with societal costs. Large variation in the size of birth cohorts causes problems in planning and in investing for public services such as child day care and school. In adulthood small birth cohorts face extra burden of financing welfare state services for earlier birth cohorts of larger size. This paper studies the effect of economic recessions on fertility through unemployment in Finland. We built on two recent macrolevel comparative studies by Goldstein et al. (2013) and Comolli (2017) by analyzing unemployment and fertility in a sub-regional level over a quarter of a century, that is from 1991 to 2015. 
The relationship between unemployment and fertility has been analyzed both with individual level data (e.g. Currie and Schwandt 2014; Jalovaara et al. 2017; Jalovaara and Fasang 2015, 2017; Miettinen and Jalovaara 2017; Miettinen 2015; Pailhé and Solaz 2012) and aggregate level data (e.g. Comolli 2007; Goldstein et al. 2013; Schneider 2015). Only a handful of studies have been able to combine micro- and macro-level data. Hoem (2000) studied dramatic swings in the Swedish total fertility rate (TFR) since mid-1980s with individual level register data on all Swedish women born in 1950 or later together with data on employment trends in their home municipality. The analysis showed that first-birth rates rose and fell in step with municipal employment levels. Neels et al. (2013) were also able to use both macro-level indicators and longitudinal microdata for 14 European countries to demonstrate that adverse economic conditions and high unemployment significantly reduce first birth hazards among men and women below age 30. By utilizing register-based birth, migration, education and unemployment histories for the complete Norwegian population between 1992 and 1998 Kravdal (2002) was able to show that unemployment had a negligible impact on fertility through individual-level effects but significant impact through aggregate level effects. Microlevel data allows detailed analysis of specific fertility responses of unemployment, for example postponement, renouncement of first births, intervals between subsequent births, decreasing numbers of higher-order births and the effects for specific population groups. The benefit of macro-level analysis is that it allows to combine different components of fertility response. The estimates on the aggregate fertility impact of unemployment to fertility may thereby, for example, facilitate discussion on social consequences of economic recession.

With regard to fertility and unemployment Finland makes an interesting case. After the Second World War Finland enjoyed four decades of almost uninterrupted economic progress but then experienced two long periods of economic decline within 25 years. In the early 1990s, Finland entered a deep recession as a result of overheating of the economy and the collapse of trade with the Soviet Union. During 1991-1993, GDP dropped by $12 \%$ and the unemployment rate increased from negligible level to above $20 \%$ (Kalela et al. 2001). The 1990s recession in Finland was over by 1994, even though the employment rate recovered more slowly, and the low levels of unemployment of the 1980 were never reached again (Figure 1). In the late 1990s, the country experienced Nokia-led high-tech boom and rapid economic growth, which lasted until the economic collapse in 2008. Since then the economy stagnated until early 2017 when first signs of robust economic growth were finally visible but volume of economic output was still clearly below pre-2008 level. The recession beginning in 2008 has been characterized as the lost decade of economic progress. The effects of these drivers of unemployment have caused considerable regional variation among sub-regions in Finland. 


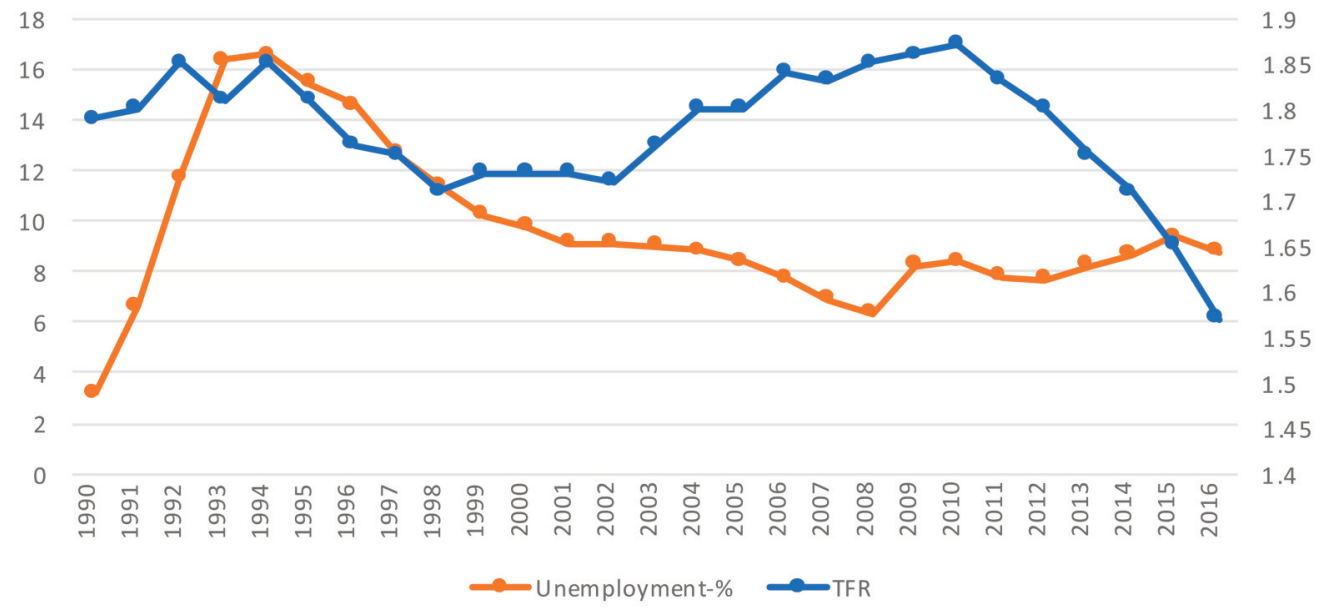

Figure 1. UNEMPLOYMENT (\%) and total fertility rate in Finland, 1990-2016. Source: Findicator 2017.

Together with other Nordic countries and United States Finland maintained comparatively high fertility (TFR between 1.59 to 1.79 throughout the 1980s) before the economic shocks. The recession in the 1990s did not immediately decrease fertility. On the contrary, TFR climbed to 1.85 in 1994 and then, as recession continued, started to fall until 1998 when it hit 1.71 (Figure 1). The strong upswing in the economy was associated with increasing fertility in the late 1990s and in the beginning of the new millennium. Finland had record high fertility of 1.87 in 2010, again two years after the beginning of the recession in 2008. Since 2010 fertility has been steadily declining, TFR reaching 1.57 in 2016.

The decline in fertility during the Great recession in Finland is remarkable also from a comparative perspective. Fertility declined by 0.3 births per women between 2010 and 2016. Among 31 European countries and the United States the strongest decline in fertility between 2008 and 2013 was experienced in Iceland (-0.27) and the United States (-0.22) (Comolli 2017:1560).

Previous research from single country and comparative settings has demonstrated that unemployment is the key mechanism explaining the aggregate level procyclical 
relationship between fertility and economic growth (Comolli 2017; Goldstein et al. 2013). The possible mechanisms concern both uncertainty's effect on reproductive behavior and partnership formation. Evidence seems to indicate that unemployment affects timing of first childbearing rather than completed fertility. With data from France, Pailhé and Solaz (2012) showed that periods of insecure employment delay fertility for women, while male unemployment has a negative influence on completed fertility only among those men who have faced long-term unemployment. Together with more limited financial capacity unemployment is associated with feelings of shame and depression, which might not make unemployed persons desirable partners. Unemployment also increase union instability (Lyngstad and Jalovaara 2010). A recent study from Finland shows that childlessness has been most common among low educated men and is increasingly so also for low educated women (Jalovaara et al. 2017). The results are linked with the fact that low educated have more fragmented partnership histories (Jalovaara and Fasang 2015, 2017).

General micro-economic theory relates to childbearing and unemployment among individuals with available partners (Becker 1993). The income effect suggest that higher income and more secure earnings promote childbearing. This effect is most relevant for men who do not bear costs of childbearing in terms of unpaid care work to the extend women do. This is the case even in the Nordic countries which are known as most egalitarian in the world (Björnberg and Ottosen 2013). Childbearing comes also with price effect, or opportunity cost effect, which takes into account both the direct costs of children and the lost earning as a result of time devoted for taking care of the children.

The micro-economic theory implicates that a short economic recession might not decrease fertility since female unemployment reduces opportunity cost of childbearing (Butz and Ward 1979). However, it is difficult to detect if such effect exists. If macro level fertility levels begin to increase or remain unchanged after a short recession period that could merely reflect the growing optimism and decreasing unemployment rather than women taking advantage of their short unemployment period for child bearing. The income and price effect of unemployment to fertility may not only differ by gender but also by education, age, parity and business cycle. Most empirical studies have found a negative association between longer economic recession and fertility.

For partnered couples experience of unemployment comes with insecurity both in terms of current and prospective income and in terms of housing. The effect may be aggravated if cultural norms dictate that young couples should be well equipped before having children. In any case, the couples suffering from unemployment might be hesitant to consider having a baby since it puts family finances under extra stress. They may also need to prepare for getting a new place to live if they are forced to move in search of a new job or if they cannot afford the current house or apartment. These effects concern not just those who experience unemployment but all who fear losing their jobs or not having a job in the first place. During economic recessions negative business news dominate public space, which may exacerbate the effect of the fear factor. 
When entering recession young couples do not know how long the recession might last. Losing a job at the first phase of economic downturn or failing to find one might offer a recess from labor market to have a child. Earlier research before the Great Recession showed that the effect of economic recession on fertility is small and temporary (Currie and Schwandt 2014). This has been explained by the absence of long-term economic declines among the high-income countries. The more recent research on the Great Recession show substantial effects. Scheider (2015) studied national and local employment conditions during the Great Recession in the United States. General Fertility Rate declined by 0.6 births by per percentage point increase in unemployment at the state level (after controlling for demographic characteristics of the state and adding state and year fixed effects). Similar results have been obtained from Europe (see Comolli 2017 for review).

Goldstein et al. (2013) analyzed the effect of unemployment on fertility in $28 \mathrm{Eu}-$ ropean countries between 2000 and 2010. Conforming the earlier findings the study showed $0.2 \%$ decline in first birth rates among 15-19-years-old women and a decline of $0.1 \%$ among 20-24-year-old women per one percent increase in unemployment. Following the methodology developed by Goldstein et al. (2013) Comolli (2017) investigated the fertility response of the Great Recession between 2000 and 2013 in 31 European countries and the United States. One percentage increase in total unemployment was associated with $0.08 \%$ reduction in TFR. The corresponding figure for female unemployment was 0.09 .

Previous individual-level studies from Finland allow us to assume a negative relationship between unemployment and fertility (Miettinen 2015; Miettinen and Jalovaara 2017). For example, a register study with individual level data in Finland shows that a less secure labor market attachment tends to delay entry into parenthood among both men and women, especially among highly educated and older (30+ years) individuals (Miettinen and Jalovaara 2017). The study also indicated that among young women with the lowest level of education, unemployment - even long term or recurring - is likely to promote first childbearing. The aim of this study is to produce an estimate of the aggregate impact of unemployment to fertility in a country which has suffered two major recession within a quarter of a century.

\section{Data}

The study is conducted on sub-regional level including data from 69 sub-regions from 1991 to 2015. Finland is divided into 70 sub-regional units ("seutukunta" in Finnish or "ekonomisk region" in Swedish). The sub-regions are formed by groups of municipalities within the 19 regions of Finland. Our data is derived from a national indicator data bank Sotkanet (www.sotkanet.fi). This database combines resources from Statistics Finland, Eurostat, the National Institute for Health and Welfare and other sources for open source use, allowing for reproducible research. To reduce random variation we 
excluded one sub-region in the autonomous territory of Åland (Ålands skärgård) which is clearly smaller than the second largest sub-region (2419 in 1991 vs. sub-region of Joutsa 7137 in 1991) leaving us with a final sample of 69 sub-regions and 1,656 observations $(69 * 24)$. Focusing on sub-regions instead of municipalities allows us to better eliminate the effect of migration within sub-region's municipalities and control for spatial trends in fertility rates (e.g. Lainiala and Berg 2016). It also reduces random variation inherent in the large number of small municipalities and allows us to include the total population (with the exception of Ålands skärgård) into the analysis.

The downside of using Sotkanet database is that it does not have detailed fertility data, for example age, education or parity specific fertility. The only available measure of fertility is delivery rate per 1,000 women aged 15-49 (Sotkanet indicator number 677). The indicator gives the annual number of deliveries per thousand women of fertile age (15-49). Delivery rate differs from the three commonly used fertility indicators: Birth rate is the annual number of live births per thousand. General fertility rate is the annual number of live births (not deliveries) per thousand women of fertile age (1549). Total fertility rate is the calculated number of live-born infants that would be born to thousand women if they were to live to the end of their child-bearing years and bear children at each age in accordance with the age-specific fertility rates of the year concerned. Assuming that the share of multiple pregnancies remain stable delivery rate reflects changes in general fertility rate.

We study the effect of recessions through unemployment, which is measured as the share of unemployed people of labour force (Sotkanet indicator 181). The data is derived from the Employment Service Statistics of the Ministry of Employment and the Economy that draw on data in the client registers of employment and economic development offices. The unemployment figures based on the Labour Force Survey and those given in the Employment Service Statistics differ from each other. This is due to the fact that they use different principles in compiling the statistics with respect to the degree of activity shown in job seeking and the jobseeker's availability for work. The Ministry's Employment Service Statistics are based on legislation and administrative provisions. Statistics Finland's Labour Force Survey, in turn, follows the recommendations of the International Labour Organisation (ILO) and the practices required by Eurostat, the Statistical Office of the European Communities. The total average number of the unemployed during the year is given as an average calculated by the number of unemployed job seekers (unemployed and entirely laid off individuals whose work application is active on the day of calculation) on the last day of each month. We use unemployment figures for whole population and separately for males and females.

Our measure of educational level describes the educational level of a population group by the length of education per person (Sotkanet indicator number 180). For example, the value 246 shows that the theoretical length of education per person is 2.5 years after completing basic education (data is not available by gender). The Register of Completed Education and Degrees is based on data on educational qualifications and degrees collected directly from educational establishments. The measure is appli- 
cable in comparing the level of education between different geographical areas and monitors changes over time.

Our measure of fertility takes into account the number of women in fertile age (1749). However, changes in the composition of women in this age group is likely to affect fertility. Over the period of investigation women between 25 and 34 years of age had children most often (SVT 2015). To control for this fact we use the number of women between 25 and 34 years of age in the sub-region as control variable. The data is derived from Sotkanet variable for "Population by 5-year age group" (indicator numbers 991 and 992) which gives the sub-region's permanent resident population on the last day of the year in each 5-year age group by sex.

\section{Methods}

Using time series (trend) data collected on sub-regional level from Sotkanet statistics, we test the hypothesis that unemployment would be negatively associated with fertility. We take advantage of changes in unemployment to model the effects of unemployment on fertility while controlling for the inherent heterogeneity of sub-regions. There is a large variation in fertility level across different localities in Finland (Table 1). For example, the presence of the revival movement Lestadians, known for its natural fertility emphasizing family values and guidelines including pre-marital abstinence and refraining from the use of contraception, influence fertility levels (Terämä 2010). The subregion of Nivala-Haapajärvi, one of the strongholds of the revival movement, had a delivery rate of 79.3 in 2008 while the country average for the observation period was 47.4.

We use regression models with sub-region fixed effects to assess how changes in unemployment (all, males, females) is linked to fertility in Finnish sub-regions between 1991 and 2014. Sub-region fixed-effect models make it easier to differentiate between differences in fertility due to inherent characteristics of specific sub-regions (for example due to dominant religious sects in the area) and those that result from increasing (or decreasing) local unemployment (Bell and Jones 2015).

Between 1991 and 2014 unemployment has fluctuated dramatically within the subregions (for total unemployment $\min 1.3 \%$, max $30.2 \%$, Table 1). To capture the specificities of two periods of recession, we constructed dummy variables for three time periods: between 1991 and 1999 (period 1), between 2000 and 2007 (period 2) and between 2008-2014 (period 3). The first period relates to the economic recession in the early 1990s, while the third period related to period of Great Recession. The second period relates to a time of strong economic growth when unemployment decreased considerably in Finland (see Figure 1). To determine the effect of the different time periods on unemployment and fertility trajectories we calculated interaction of second and third period and unemployment. It is important to note that the dynamics of childbearing and education may also have shifted in the course of the observation periods. To control for this fact we calculated interaction of second and third period and education. 
Following the methodology applied by Goldstein et al. (2013) and Comolli (2017) we use one year lag in fertility (fertility is analyzed over period 1992-2015). Additionally, we construct models where fertility is lagged by two years. We use log-log models where all variables are log-transformed to estimate the association between the recession and fertility in terms of elasticity of fertility rates to each indicator. These models allow to smooth large variation in the variable values and to detect non-linear relationships. Statistical analysis were carried out with statistical software R's plm-package (Croissant and Millo 2008).

Table 1. BASIC characteristics of used variables from 1991 to 2015.

\begin{tabular}{|l|c|c|c|c|c|c|}
\hline Variable & Observations & Min & Max & Median & Mean & $\begin{array}{c}\text { Standard } \\
\text { deviation }\end{array}$ \\
\hline Fertility & 1656 & 27.1 & 79.3 & 47.4 & 48.5 & 7.7 \\
\hline Unemployment & 1656 & & & & & \\
\hline- all & & 1.3 & 30.2 & 13.4 & 13.9 & 5.3 \\
\hline- male & 1.3 & 32.9 & 13.7 & 14.4 & 5.8 \\
\hline- female & 1656 & 145 & 409 & 246 & 247.5 & 50.4 \\
\hline $\begin{array}{l}\text { Education } \\
\begin{array}{l}\text { Population } \\
\text { females } \\
\text { between 25 } \\
\text { and 34) }\end{array}\end{array}$ & 170 & 113731 & 1759 & 4842 & 12900 \\
\hline
\end{tabular}

\section{Results}

Firstly, we analyze fertility response from 1992 to 2015 to unemployment from 1991 to 2014 (fertility lagged by one year) (Table 2). As expected unemployment was negatively associated with fertility. One percentage increase in unemployment decreased fertility by 0.13 percentages $(\mathrm{p}<0.001,95 \% \mathrm{cl}-0.11-0.15)$ between 1992 and 2015. Education was negatively associated with fertility, while change in the number of women in fertile age were positively associated with fertility. There were no major differences in fertility response of unemployment between different measures of unemployment (total, male, female). The interaction between unemployment and period between 2008 2014 was positive and statistically significant $(0.06, \mathrm{p}<0.001,95 \% \mathrm{cl} 0.009-0.02)$ indicating that the fertility response to unemployment was stronger during the Great Recession than during the economic recession in the 1990s (period between 1991 and 1999). There was a weak indication that the dynamics of unemployment, education and 
fertility changed during the Great Recession. The interaction term for education on fertility response of female unemployment was negative $(-0.02, \mathrm{p}<0.01,95 \% \mathrm{cl}-0.005$ $(-) 0.03)$ indicating that education was no longer negatively associated with fertility the way it was during the 1990s.

Table 2. RESULTS from three panel fixed effect regression models with one year lagged fertility as outcome.

\begin{tabular}{|l|l|l|l|}
\hline Unemployment & Model 1 & Model 2 & Model 3 \\
\hline- total & $-0.13^{* * *}(0.10-0.15)$ & & \\
\hline- male & & $-0.11^{* * *}(-0.09-(-) 0.13)$ & \\
\hline- female & & & $-0.12^{* * *}(-0.10-(-) 0.14)$ \\
\hline Education & $-0.38^{* * *}(-0.22-(-) 0.53)$ & $-0.46^{* * *}(-0.31-(-) 0.61)$ & $-0.26^{* * *}(-0.12-(-) 0.40)$ \\
\hline Population & $0.22^{* * *}(0.18-0.25)$ & $0.21^{* * *}(0.18-0.25)$ & $0.22^{* * *}(0.18-0.25)$ \\
\hline Year & $0.003^{* * *}(0.002-0.005)$ & $0.004^{* * *}(0.002-0.005)$ & $0.003^{* *}(0.001-0.004)$ \\
\hline $\begin{array}{l}\text { Period2 } \\
\text { unemployment } \\
(2000-2007))\end{array}$ & $-0.01(-0.03-(+) 0.01)$ & $-0.02(-0.03-(+) 0.01)$ & $-0.004(-0.03-(+) 0.02)$ \\
\hline $\begin{array}{l}\text { Period3 } \\
\text { unemployment } \\
(2008-2015)\end{array}$ & $0.06^{* * *}(0.01-0.07)$ & $0.05^{* * *}(0.02-0.08)$ & $0.07^{* * *}(0.04-0.09)$ \\
\hline $\begin{array}{l}\text { Period2 } \\
\text { education } \\
(2000-2007))\end{array}$ & $0.01(-0.01-(+) 0.02)$ & $0.01(-0.001-(+) 0.02)$ & $0.002(-0.01-(+) 0.01)$ \\
\hline $\begin{array}{l}\text { Period3 } \\
\text { education } \\
(2008-2015)\end{array}$ & $-0.01(-0.03-(+) 0.001)$ & $-0.004(-0.02-(+) 0.01)$ & $-0.02(-0.005-(-) 0.03)^{* *}$ \\
\hline $\begin{array}{l}\text { R2 } \\
\text { (20) }\end{array}$ & $30.5 \%$ & $28.8 \%$ & $31.4 \%$ \\
\hline
\end{tabular}

Note: ${ }^{*} \mathrm{p}<0.1 ;{ }^{* *} \mathrm{p}<0.05 ;{ }^{* * *} \mathrm{p}<0.01$

Secondly, we calculated estimates for fertility which was lagged with two years (fertility between 1993 and 2015) (Table 3). A similar pattern for unemployment and fertility was observed. Again, the effect of unemployment to fertility was stronger during the Great Recession than during the recession in the early 1990s. Lagging fertility with two years showed that the role of education has changed during the Great Recession. 
Interaction between education and the third period (period of Great Recession) was negative and significant for two measures of unemployment $(-0.03, \mathrm{p}<0.05,95 \% \mathrm{cl}-$ $0.003-(-) 0.03$ for total unemployment; $-0.03, \mathrm{p}<0.001,95 \% \mathrm{cl}-0.01-(-) 0.04$ for female unemployment).

Table 3. RESULTS from three panel fixed effect regression models with two years lagged fertility as outcome.

\begin{tabular}{|l|l|l|l|}
\hline & Model 1 & Model 2 & Model 3 \\
\hline Unemployment & & & \\
\hline- total & $-0.13^{* * *}(0.10-0.15)$ & & \\
\hline- male & & $-0.12^{* * *}(-0.10-(-) 0.14)$ & \\
\hline- female & & $-0.50^{* * *}(-0.34-(-) 0.65)$ & $-0.28^{* * *}(-0.14-(-) 0.43)$ \\
\hline Education & $-0.40^{* * *}(-0.25-(-) 0.55)$ & $0.17^{* * *}(0.14-0.21)$ & $0.17^{* * *}(0.14-0.21)$ \\
\hline Population & $0.17^{* * *}(0.13-0.21)$ & $0.005^{* * *}(0.003-0.007)$ & $0.004^{* *}(0.002-0.006)$ \\
\hline Year & $0.004^{* * *}(0.002-0.006)$ & \\
\hline $\begin{array}{l}\text { Period2 } \\
\text { unemployment } \\
(2000-2007)\end{array}$ & $-0.008(-0.03-0.02)$ & $0.01(-0.04-0.01)$ & $-0.001(-0.02-(+) 0.02)$ \\
\hline $\begin{array}{l}\text { Period3 } \\
\text { unemployment } \\
(2008-2015)\end{array}$ & $0.06^{* * *}(0.03-0.09)$ & $0.06^{* * *}(0.03-0.09)$ & $0.07^{* * *}(0.04-0.10)$ \\
\hline $\begin{array}{l}\text { Period2 } \\
\text { education } \\
(2000-2007))\end{array}$ & $0.005(-0.01-(+) 0.02)$ & $0.01(-0.002-(+) 0.02)$ & $0.001(-0.02-(+) 0.01)$ \\
\hline $\begin{array}{l}\text { Period3 } \\
\text { education } \\
(2008-2015)\end{array}$ & $-0.02^{*}(-0.003-(-) 0.03)$ & $-0.01(0.002-(-) 0.03)$ & $-0.03^{* * *}(-0.01-(-) 0.04)$ \\
\hline \begin{tabular}{l} 
R2 \\
\hline
\end{tabular} & $26.4 \%$ & $25.2 \%$ & $27.0 \%$ \\
\hline
\end{tabular}

Note: ${ }^{*} \mathrm{p}<0.1 ;{ }^{* *} \mathrm{p}<0.05 ;{ }^{* * *} \mathrm{p}<0.01$ 


\section{Discussion}

Our results indicate that economic conditions matter for fertility (Comolli 2017; Miettinen and Jalovaara 2017; Sobotka et al. 2011). Fertility was clearly associated with unemployment between 1991 and 2015 whether we measured it with total or gender specific unemployment. The finding is in accordance with Miettinen and Jalovaara (2017) who show with register data and more detailed variables that less secure labor market attachment is likely to delay entry into parenthood.

Our results also support findings from previous studies focusing on the effects of unemployment on fertility during the Great Recession. The gross country study of Goldstein et al. (2013) demonstrated a 0.2 percentage decline in first birth rates among 15-19-years-old women and a 0.1 percentage point decline for one among women aged 20-24 per one percentage increase in unemployment. However, Goldstein et al. (2013) found practically no associations between unemployment and fertility in Finland but their data did not reach beyond year 2011. Comolli (2017) showed that in the sample of 32 countries in the period 2000-2013 one percentage increase in total unemployment rate was associated with 0.08 percentage decline in TFR next year. Our estimate of 0.13 percentage negative elasticity falls between the two estimates described above. Due to differences in data sources, methods and measures it is not possible to directly compare the results. It is worth noting, though, that Comolli's sample included countries with very small changes in unemployment during the observation period. It seems, though, that the fertility effect of unemployment has been fairly strong in Finland. It is not possible to further explore, in the scope of this study, why that would be the case. One factor could be the fact that the recessions have hit Finland exceptionally hard.

The fertility response to unemployment was stronger during the Great Recession than during the recession in the early 1990s. The results could be linked to differences in the nature of the recessions and to the fact that some individuals in child bearing age experienced the recession already for the second time. The recession in the early 1990s was abrupt crises hitting all sectors of the labor market but the employment situation began to improve after a couple of years, while the Great recession was characterized by longstanding uncertainty. In terms of policy, it is interesting to note that the statutory home care allowance (HCA) was increased in the early 1990s and many municipalities introduced municipal supplements to HCA thereby increasing the attractiveness of HCA (Haataja 2005). This might have helped to diminish the negative effect of unemployment on fertility. Also attitudes towards family and childbearing could have change. Comparison of survey responses from 1997, 2002, 2007-2008 and 2015 show that among Finns in the age group between 20 and 50 the desired number of children has decreased and the perceived ideal age to become a mother or a father has increased (Miettinen 2015). It is also worth mentioning that over the last few years fertility has decreased in all Nordic countries, also among those countries which have not experienced economic recession or which were well on the way for economic recovery (Eurostat 2017). These topics should be further investigated in the future. 
We also showed that dynamics between fertility and education changed during the observation period indicating that increase in education level was no longer negatively associated with fertility. The results aligns with Jalovaara and Fasang $(2015,2017)$ who report that in the trajectories of women and men in Finland between the ages of 18 and 39, and on the 1969 and 1970 birth cohorts the low-educated had more fragmented partnership histories and that childlessness at age 42 was more common among lesseducated women and men.

The changes in fertility levels is an often neglected effect of economic recessions. The size of birth cohorts in Finland has fluctuated strongly during the last quarter of a century. In the 1990s the biggest birth cohort was 66,731 (year 1992) while the smallest was 57,108 (year 1998). In the 2000s as many as 60,980 children were born in 2010, while only 52,814 were born in 2016. Due to the fact that Finland experienced a previous period of low fertility in the 1970 s a record low number of children were born in 2016. Last time when fewer children were born in the country was during the famine of 1866-1868. That was the last major naturally caused famine in Europe, when around 15 percent of Finnish population lost their lives. The most recent figures indicate that in 2017 even fewer children will be born (SVT 2017). Besides reflecting underlying differences in the number of women at fertile age the changes in the size of birth cohorts are linked to changes in attitudes, patterns of partnership formation and other factors (Miettinen 2015).

\section{Strengths and limitations}

We were able to use aggregate data covering 25 years and two periods of severe economic recession. The data used for the analysis was derived from Sotkanet which offers a wide range of register-based variables on population, health and social conditions. Register data are not subject to the bias characteristic to self-reported income and the self-selection of the survey respondents. The strength of the data was also that it allowed the analysis on sub-regional level to produce a rough estimate on the total effect of unemployment to fertility.

Due to data limitations we were not able carry out a more nuanced analysis of fertility response to unemployment by including age-groups, parity or partnership into the analysis. Longitudinal study can be seen as an improvement from cross-sectional studies, but is still far from a causal result, especially due to the presence of unobserved time-variant variables, such as changes in attitudes (Miettinen 2015) or income, that may confound causal effects.

Fertility response of economic recessions does not occurs solely through unemployment. Previous research has shown that mortgage foreclosures, consumer confidence and press coverage of recession (Comolli 2017; Scheider 2015) are also associated with fertility. One reason for the fact that changes in unemployment explained only a fraction of the reduction in fertility in our calculations could be that unemployment does not 
capture all dimensions in the association between economic recessions and fertility. Unemployment rate is calculated as the share of unemployed of the labor force. The recession also affect the denominator since some people stop looking for work if no work is available. An alternative strategy is to focus on employment rate which gives the share of employed people from working aged population. Besides unemployment and employment rates economic recession may influence fertility through other pathways such as changes in the housing market, interest rates or consumer confidence.

A major limitation of this approach is the possibility of so called ecological fallacy, which resulted from the non-availability of individual level data for this study. Subregions do not give birth to babies, individuals do. We were not able to determine if those suffering from unemployment were actually the same individuals how experienced reduced fertility. It is important to note, however, that unemployment is also a contextual factor which may have effects beyond individual experiences of unemployment. High unemployment signals labor market insecurity which is also felt by those in employment and by those outside the labor force (this effect is not captured in most of the individual level studies). Multilevel analysis utilizing both individual level longitudinal data and local level contextual factors are needed for more detailed analysis.

\section{References}

Becker, G. (1993). A Treatise on the Family. Enlarged edition. Cambridge, MA: First Harvard University Press.

Bell, A. \& Jones, K. (2015). Explaining fixed effects: random effects modeling of timeseries cross-sectional and panel data. Political Science Research and Methods 3(1),133-153.

Björnberg, U. \& Ottosen, M. (eds.) (2013). Challenges for future family policies in the Nordic countries. Copenhagen: SFI - the Danish National Centre for Social Research.

Butz, W. P., \& Ward, M. P. (1979). The emergence of countercyclical US fertility. American Economic Review, 69, 318-328.

Comolli, C. (2017) The fertility response to the Great Recession in Europe and the United States: Structural economic conditions and perceived economic uncertainty. Demographic research 36(51), 1549-1600.

Croissant, Y. \& Millo, G. (2008). Panel Data Econometrics in R: The plm Package. Journal of Statistical Software 27(2), 1-43.

Currie, J. \& Schwandt, H. (2014). Short- and long-term effects of unemployment on fertility. Proceedings of the National Academy of Sciences 111(41), 14734-14739. doi:10.1073/pnas.1408975111.

Eurostat (2017). Total fertility rate. http://ec.europa.eu/eurostat/

Findicator (2017). Total fertility rate in 1776-2016. www.findikaattorifi Statistics Finland.

Goldstein, J., Kreyenfeld, M., Jasilioniene, A. \& Örsal, D. K. (2013). Fertility reactions to the 'Great Recession' in Europe: Recent evidence from order-specific data. Demographic Research 29(4), 85-104.

Haataja, A. (2005). Outcomes of the Two 1990s Family Policy Reforms at the Turn of the 2000s in Finland. Yearbook of Population Research in Finland 41, 5-27.

Hoem, B. (2000). Entry into motherhood in Sweden: the influence of economic factors on the rise and fall in fertility, 1986-1997. Demographic Research 2(4), doi:10.4054/DemRes.2000.2.4. 
Jalovaara, M., Neyer, G., Andersson, G., Dahlberg, J., Dommermuth, 1., Fallesen, P., and Lappegaird, T. (2017). Education, gender, and cohort fertility in the Nordic countries. Stockholm Research Reports in Demography 2017:6.

Jalovaara, M. \& Fasang A. (2017). From never partnered to serial cohabitors: union trajectories to childlessness. Demographic Research 36(55), 1703-1720.

Jalovaara, M. \& Fasang, A. (2015). Are there gender differences in family trajectories by education in Finland? Demographic Research 33(44), 1241-1256.

Kalela, J. \& Kiander, J. \& Kivikuru, U. \& Loikkanen, H. \& Simpura, J. (eds.) (2001). Down from the Heavens, Up from the Ashes. The Finnish Economic Crisis of the 1990s in the Light of Economic and Social Research. VATT Publications 27:6. Helsinki: Government Institute for Economic Research.

Kravdal, O. (2002). The impact of individual and aggregate unemployment on fertility in Norway. Demographic Research 6(10), 263-294.

Lainiala, L. \& Berg, V. (2016). Spatial trends of fertility rates in Finland between 1980 and 2014. Finnish Yearbook of Population Research 51, 89-95.

Lyngstad, T. \& Jalovaara, M. (2010). A review of the antecedents of union dissolution. Demographic Research 23:257-292.

Miettinen, A. (2015). Miksi syntyvyys laskee? Suomalaisten lastensaantiin liittyviä toiveita ja odotuksia. Perhebarometri 2015. Helsinki: Väestöliitto.

Miettinen, A. \& Jalovaara M. (2017). Stable employment - more babies? Life stage and educational differences in the effects of labour market attachment on first births among Finnish men and women (manuscript).

Neels, K., Theunynck, Z., \& Wood, J. (2013). Economic recession and first births in Europe: recession-induced postponement and recuperation of fertility in 14 European countries between 1970 and 2005. International Journal of Public Health 58, 43-55.

Pailhé, A. \& Solaz, A. (2012). The influence of employment uncertainty on childbearing in France: A tempo or quantum effect? Demographic Research 26(1), 1-40.

Schneider, D. (2015). The Great Recession, fertility, and uncertainty: Evidence from the United States. Journal of Marriage and Family 77(5), 1144-1156. doi:10.1111/ jomf.12212.

Terämä, E. (2010). Regional Demographic Differences: the Effect of Laestadians. Finnish Yearbook of Population Research 45, 123-141.

Sobotka, T. \& Skirbekk, V. \& Philipov, D. (2011). Economic recession and fertility in the developed world. Population and Development Review 37(2), 267-306.

Suomen virallinen tilasto (SVT) (2017). Väestön ennakkotilasto [web publication]. ISSN=1798-8381. May 2017. Helsinki: Statistics Finland [19.7.2017]. Available at http://www.stat.fi/til/vamuu/2017/05/vamuu_2017_05_2017-06-22_tie_001_fi.html 